\title{
The implementation and role of geotechnical data in BIM process
}

\author{
Merdan Berdigylyjov ${ }^{1, *}$, and Horațiu Popa $^{1}$ \\ ${ }^{1}$ Technical University of Civil Engineering of Bucharest, Geotechnical and Foundation Department, Romania
}

\begin{abstract}
Building Information Modeling (BIM) is becoming increasingly important tool in civil engineering both in the infrastructure design and construction process. BIM uses an intelligent model that provides a faster, more economical and less environmental impact for building and managing construction and infrastructure projects. Intelligent information model enable rich visualization, simulation and collaboration, which together allow better decision making throughout the project team. Major infrastructure projects that have a significant geotechnical and structural aspects may implement BIM tools and processes but often seem to neglect the geotechnical aspect of the model. This omission can lead to costly mistakes especially when the project is infrastructure-based. This paper reviews the current BIM implementations on major infrastructure projects and overseas and reviews how the inclusion of the geotechnical data in the BIM model can improve the models usefulness and the decision making process. The paper also investigates the reasons why the geotechnical data is not included and how these barriers can be removed so that the geotechnical and structural teams a fully integrated. The paper ends with a set of recommendations that, if adopted, could allow the engineering design team to produce innovative geotechnical systems and improve the cost effectiveness of construction.
\end{abstract}

\section{Introduction}

Building Information Modeling (BIM) has grown massively in recent years. If the use of BIM in superstructure projects is well implemented, for the infrastructure projects it remains uncommon. However, infrastructure works are often those that involve the highest risks, as well as significant costs.

There are many definitions of Building Information Modeling (BIM), but the National Building Information Model Standard Project Committee [1], in the USA, defines BIM as: "Building Information Modeling (BIM) is a digital representation of physical and functional characteristics of a facility. As such, it serves as a shared knowledge resource for information about a facility, forming a reliable basis for decisions during its life cycle from inception onward". ${ }^{1}$

In simple terms: "BIM is sharing information in a more structured, intelligent and timely fashion". ${ }^{2}$

BIM is multidisciplinary and everyone involved must work together. This intelligent process based on the model should provide insight into the creation and management of construction and infrastructure projects faster, more economically and with less impact on the environment. BIM software portfolio should include integrated solutions for design, visualization, modeling and collaboration that use rich information in a reasonable model to better inform decision-making and break down barriers to a better business.

\section{General principles of BIM}

BIM principles can be applied to geotechnics to help reduce uncertainty and produce a better site investigation which will help to reduce risk and cost.

BIM has three main principles and a digital data enabler when applying it to Geotechnical Engineering, [2]:

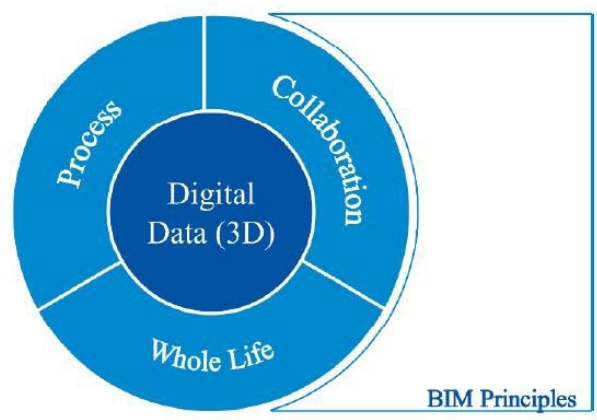

Fig. 1. BIM principles, [2].

Process - BIM demands agreed repeatable operations, methods and workflows, to let data and information to be prompt captured, processed and shared.

Collaboration - benefits of BIM are required by visualizing and analyzing data with information from another disciplines, therefore providing engineers see the big picture and can make decisions that are more informed.

Whole Life - refers to retaining and building on data and information assembled during the life of the project

\footnotetext{
${ }^{2}$ Neil Chadwick, October 2015
}

${ }^{1}$ US National BIM Standard Project Committee

\footnotetext{
* Corresponding author: nadrem1992@gmail.com
} 
so that it can be reused and improved. Information is frequently lost and has to be relearnt at each phase of the project. By managing data and information, it can be used during the life of the structure and perhaps in the future.

Digital data (3D) - is the core and enabler what lets the advantages of BIM to be reached. For BIM to do well, general certain formats need to be used. The United Kingdom and different parts of the world have standards for geotechnical data, AGS (Association of Geotechnical and Geo-environmental Specialists, www.ags.org.uk/data-format ), in the US the DIGGS (Data Interchange for Geotechnical and Geoenvironmental Specialists, www.diggsml.org ) format is beginning to appear as the primary format. Both formats allow the transfer of geotechnical data inside and among organizations. When utilizing data interchange standards, drawing up geotechnical data requires importing the data from the data interchange file into the selected geotechnical data management system.

\section{Geotechnical Data Management}

BIM allows access to data in real time, and gives the ability to refocus sampling and testing in the middle of investigation. Unexpected ground conditions continue to be one of the main reasons for delays in the implementation of the project and inaccurate estimates in construction. Building information modeling for the subsurface can significantly improve that, but the need to export and share geotechnical data is still far from common practice. Long-term cost savings are the most recognized and documented the advantages of BIM.

BIM often seems to start from the surface upwards, not paying attention to the risks hidden by the subsurface. But there are various benefits to applying BIM principles to geotechnical data management and including geotechnical data in BIM.

The data is converted into information and presented to the client by means of borehole logs, site plans and charts. Therefore, it is important that the site investigation data is available in a format that can be embedded by the consultant or BIM teams regardless of the software they use. The standardisation of electronic data deliverables has significant advantages for the data provider and the data producer on any project, especially if the standardisation adopted is already used by both parties, [3].

\section{Examples of BIM in geotechnical engineering}

\subsection{The Silvertown Tunnel}

One of the works in which BIM has been successfully used is Silver town tunnel project, [2]. "To reduce the overall project cost and risk, we needed ways to better see and understand subsurface soil conditions in the context of existing built conditions, and calculate earthwork quantities and areas that will be impacted by construction."3

The responsible for London's transport system, is planning a modern road tunnel under the River Thames in East London. The suggested Silvertown Tunnel between Silvertown and North Greenwich will facilitate the strain on the nearby Blackwall Tunnel.

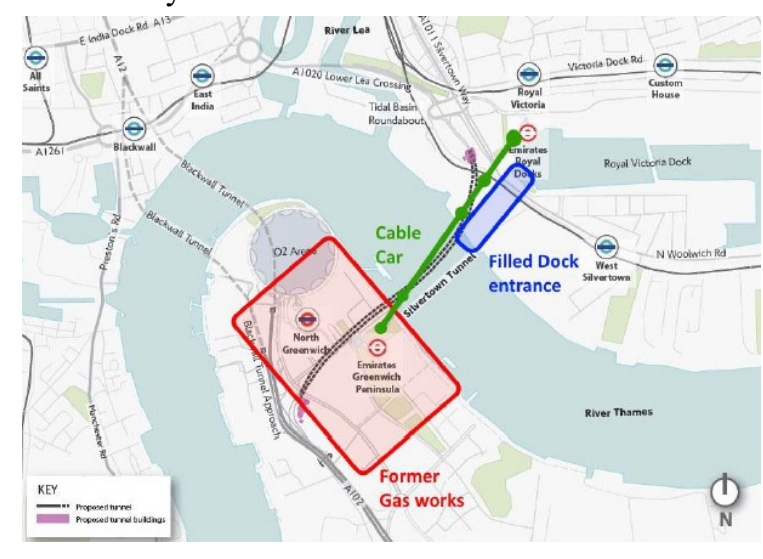

Fig. 2. Tunnel alignment challenges, [2].

There are many challenging problems: the south gate of the tunnel way is the place of a destroyed gas works. The ground in that area is polluted and there are still remnants of the underground foundations of the factory. On the south and north banks, the tunnel location comes close to the pylon foundations of the Emirates Air Line cable car. Moreover, the north bank tunnel gate is in the area of the now-filled western entrance to the Royal Victoria Dock and some destroyed warehouses.

The direction of the tunnel will thread through heavily industrialized areas. Areas with many different ground conditions, roads, foundations and other subsurface structures.

Atkins realized that they need a better way to visualize and understand the soil conditions to reduce the common project costs and risk. One example was to have a better way of estimating the amount of polluted soil that would be affected by construction. The cost of processing polluted materials makes exact calculations of the volume to assess financial implications.

The geotechnical engineers had information for the site, from historic maps to more recent projects with a digital data. By using this information they realized it would be a sizeable help in understanding the site conditions and let them to design an improved site investigation. Geotechnical engineers decided, comparing the available geotechnical knowledge in a geotechnical data management system, and developing a 3D ground model of the site and ground conditions. Then integrated to create a $3 \mathrm{D}$ geotechnical model with a purpose of permanently improving the geotechnical data and model during the all process.

Atkins has used standard methods and processes for managing their different geotechnical works. The use of standardization enabled them to collate geotechnical data from different projects. The project team had access to different historic maps and plans with destroyed gas

${ }^{3}$ Simon Miles, geotechnical engineer, Atkins 
works, warehouses, and foundations of the old dock entrance. Also team had access to created 3D models including tunnel alignment and other structures.

Project team collated and imported geotechnical data from the early projects into the new project, HoleBASE SI developed by Keynetix. The process was simple as the data was accessible in the general AGS format permitting them to share that digital data. Atkins had to provide that a common datum was used throughout whole imported projects together with standard geology classifications.
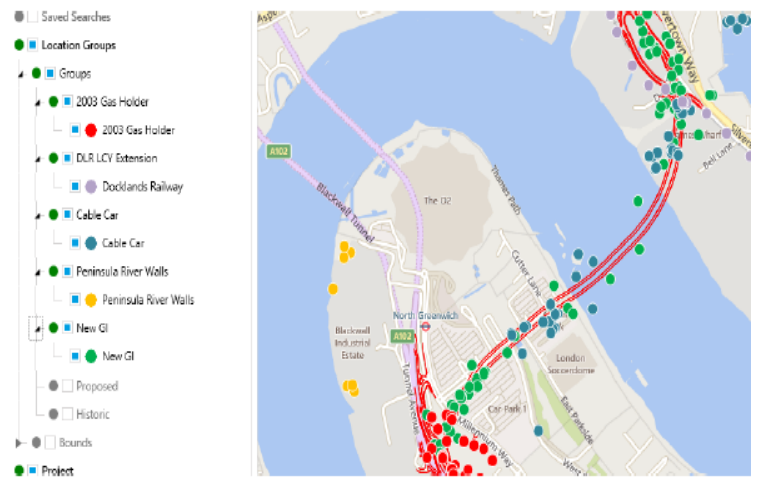

Fig. 3. HoleBase SI showing existing and new borehole locations, [2].

Atkins used AutoCAD Civil 3D to create the existing conditions of the project model. One of the advantages of using a DWG, much of the data was already in the format DWG. Before combining all of the datasets into one ground model, project team also had to provide that they all used the same coordinate system and datum. It was united together within Navisworks to let the collaborating teams to see how the model integrated. HoleBASE SI allowed for the geotechnical data in the system and to be easily integrated with AutoCAD Civil 3D. It also enabled the geotechnical data from the management system to be visualized within the $3 \mathrm{D}$ ground model.

"The HoleBASE SI Extension for Civil 3D streamlined the flow of information from our site investigation and testing to drawing production and visualization. As a result, we had more time to refine our design and were more responsive to changes from new geotechnical data." 4

The software used allowed subsurface models representing the geology layer to be created within AutoCAD Civil 3D directly from the geotechnical data stored in HoleBASE SI. The primary model, automatically created, needed manipulating and cleaning up. This process was performed by the team using all accessible information together with functionality within the selected software. One of the main advantages was that it aided the project team to visually understand and estimate the design alignment, accurate construction obstructions, and decide what new site investigations were required.

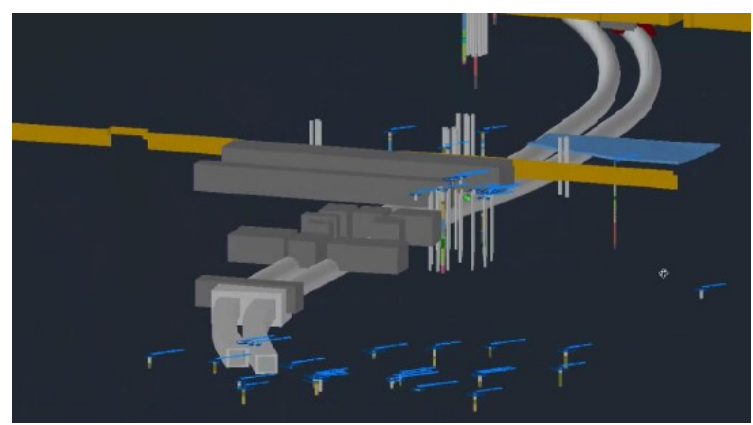

Fig. 4. 3D Boreholes and possible obstructions, [2].

By analyzing the historical and available data within the model environment they reduced the number of research holes necessary for the site investigation, which reduced project time and cost. The new site investigation data was supplemented to the project in the geotechnical data management system, and used to further improve the 3D geotechnical model to allow better understanding of the ground conditions.

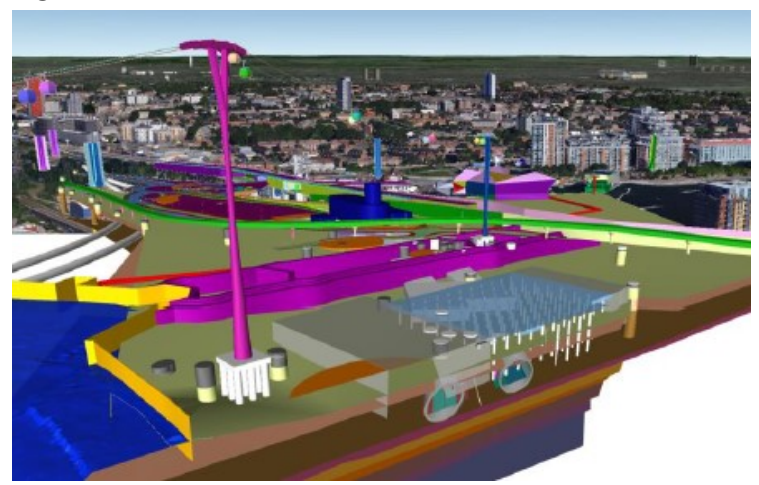

Fig. 5. The combined geotechnical model, [2].

The link between the HoleBASE SI geotechnical database and the AutoCAD Civil 3D model, which admitted them to have a rapid workflow and enabled updated geotechnical data to be prompt, viewed with the larger model. The savings in the time gave them more time to further improve the project design. Additionally, it also aided to automatically generate earthworks and pollution quantities for project costing and risk evaluation.

\subsection{United Kingdom - M25 widening}

The second example is M25 widening, [3]. One of the busiest highways in Europe, which turns over London, is M25 motorway. In 2009, the British Highway Agency awarded a contract value $\$ 10$ billion to Connect Plus consortium for tomorrow's growth, procedures and maintenance of the M25 motorway. Part of that contract involves widening over 23 miles of the highways north western sector and 17 miles in the northeast from 3 lanes to 4 .

\footnotetext{
${ }^{4}$ Jerome Chamfray, BIM manager, Atkins
} 


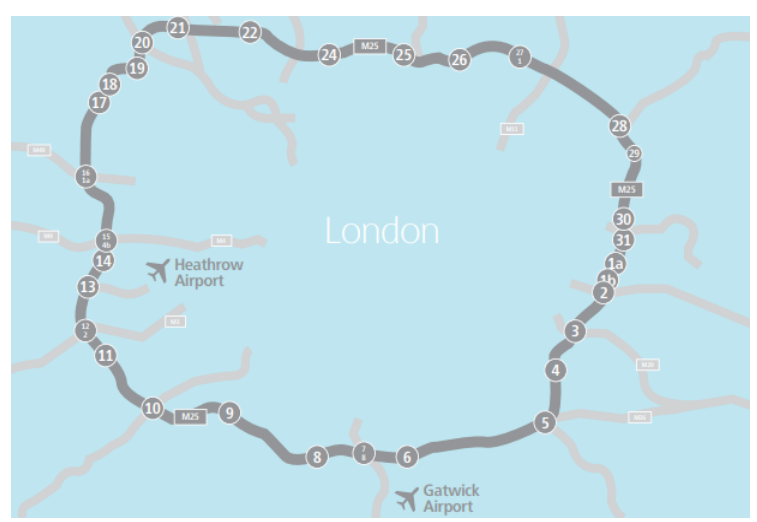

Fig. 6. M25 Motorway, [4].

Construction started in 2009 and must be accomplished before the London 2012 Summer Olympic Games. This demands finishing construction in approximately half the time it typically takes for a project of this scope.

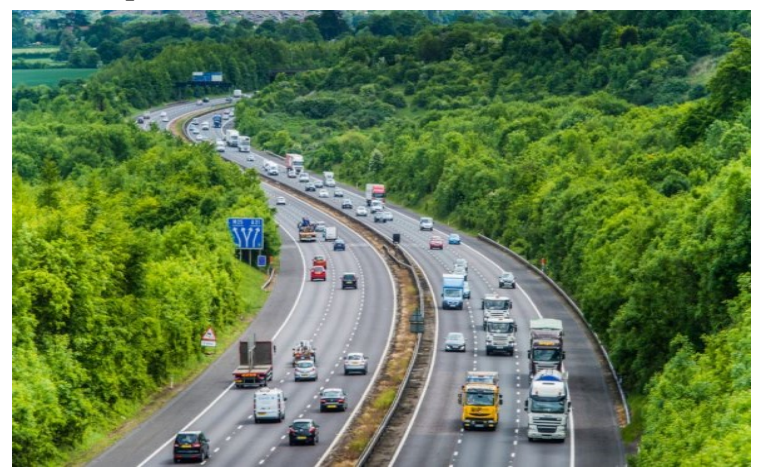

Fig. 7. M25 Motorway, United Kingdom, [4].

To help meet the aggressive design-build schedule, the project team leans on a coordinated and exact design model, which helps the team visualize the entire project, including all above ground and underground components, and non-physical aspects of the project, such as security and access zones. The designers utilize software technology to help identify and correct clashes that would be very difficult to find applying $2 \mathrm{D}$ documentation.

The project team can look the construction model from their interim offices. Using integrated, more exact model of the building means that everyone can have access to the same date last, more realistic project data when evaluating how best to carry out the construction problem.

On the M25 Widening project, the use of BIM has supplied the effectiveness needed to let the design and construction teams to see the demanding program and reduce risk. A coordinated, exact, integrated 3-D design model is depended on by the design and construction teams to visualize the all project both above and below ground. Additionally to the physical aspects of the design, non-physical aspects like safety and admission zones were included in the model. The software used to advance and coordinate the model enabled the team to identify and resolve impact in advance of building, which would have been very difficult to do precisely applying traditional methods.
On reducing construction mistakes, BIM model has had a positive influence. This has admitted the project team to construct elements right and help the necessity for expensive and time-consuming remedial works. BIM is a useful instrument that has been used by the team during the process to value engineer elements of the widening works.

The model makes it easily to look and understand the project. Screen shots and fly-through from the BIM model admitted the design to be more understood so that potential problems could be resolved in the office rather than on site. This allowed the project team to demonstrate that elements will work within the common scheme in a virtual model before building them out on site. Adding further aspects to BIM models for future projects will have time and cost profits and allow project teams to make informed decisions from an earlier phase, reduce risk and save time and costs. Experience has displayed that it would have been extremely difficult for the team to supply the design and construction of the widened section of the M25 without the use of BIM. It's a beneficial instrument for major, complex and bespoke civil engineering projects, and its use on the M25 project has set a benchmark for future large highways projects, [5].

\subsection{China and Russia connected by the Amur River Bridge}

The third example is the bridge between China and Russia on Amur River, [6]:

Industry: Road

Products: Micro Station, Project Wise, RM Bridge, Open Bridge Modeler, Open Roads, AECOsim Building Designer, ProStructures, and ProSteel

User: Long Jian Road \& Bridge Co., Ltd.

Country: China

The Heihe - Blagoveshchensk Heilongjiang River (Amur River) Bridge is being built at a total cost of CNY 2.4 billion. It will join Heilongjiang Province, China to Amur State, Russia. The Long Jian Road \& Bridge Co., Ltd. is responsible for all civil construction for the 19.9 $\mathrm{km}$ Amur River Bridge project. Bentley technology helped Long Jian Road \& Bridge Co., Ltd. solve engineering issues it faced in a complex construction environment, enabling high levels of collaboration and growing project management performance by $25 \%$ on the project.

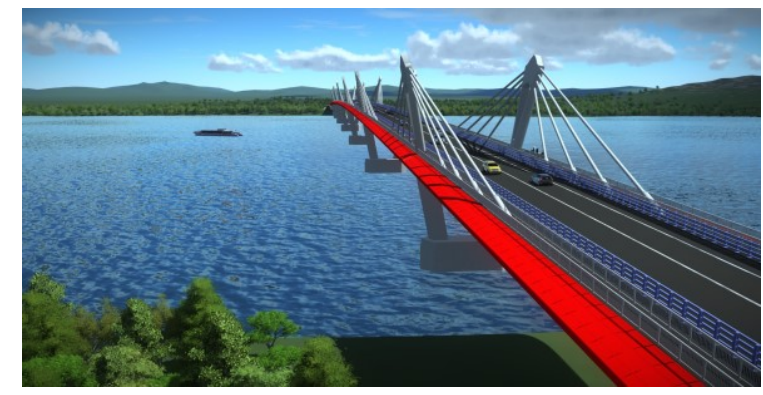

Fig. 8. Amur River Bridge connecting Russia and China, [6]. 


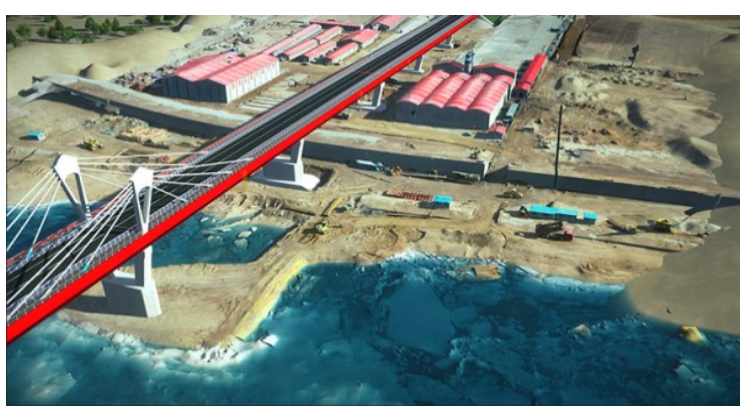

Fig. 9. Amur River Bridge connecting Russia and China, [6].

This project forms an important part of China's Silk Road economic area, as the first road bridge over the Heilongjiang River. In 2016, started construction of the $1284 \mathrm{~m}$ Amur Bridge, which connects the $6.5 \mathrm{~km}$ Chinese section from Changfatun, Heihe City with a $13.4 \mathrm{~km}$ Russian section to Canikulgan Village, Blagoveshchensk City. The team met quality and cost objectives through the use of Bentley software, leveraging Open Bridge Modeler's 3D parametric modeling to get the necessary precision steps for the bridge's superstructure and RM Bridge's finite element analysis to simulate pile foundations and main beam and other structures to optimize structural strength, rigidity, and stability.

\subsection{China - Tianjin Architecture Design Institute}

The forth example is Tianjin architecture design institute, [7]. In 2016, China accepted its 2016-2020 National Fitness Plan that goals increased sports involvement and fitness across the country, in addition growing the sports industry. The plan also includes ambitious construction for fitness facilities and infrastructure to ensure closer proximity and accessibility for both urban and rural residents.

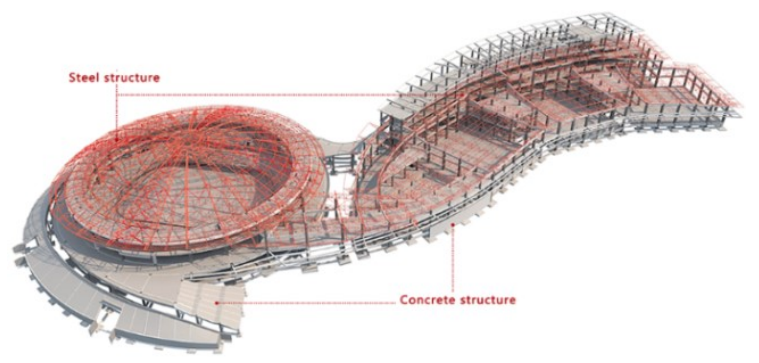

Fig. 10. China - Tianjin Architecture Design Institute, [7].

With an expected completion date in 2019, the Hohhot City Saihan District National Fitness Center Project in Inner Mongolia is being designed and constructed as part of the country's plan and to inspire involvement. The building is separated into two zones, with a site consisting of $91,437 \mathrm{~m}^{2}$ and a total construction area of $33,000 \mathrm{~m}^{2}$. Zone $\mathrm{A}$ is a multi-functional gymnasium with 5,000 seats for sports events and zone B houses the fitness center with a swimming pool, tennis courts and basketball courts.
"BIM is being applied in our whole design process, and we are achieving our 3D design goals for a very complex building. Drawings from the BIM model fully express the entire project to avoid misunderstanding and the extracted parametric model information instructs the construction with pre-cast fabrication and on-site assembly efficiently and economically".5

The whole project includes BIM. Tianjin Architecture Design Institute placed a large focus on the use of generative design to look structural components to tightly fit the finished area, reducing material losses. The nonlinear design and optimization of the fitness center was made possible over parametric modeling.

A key element for the project was to enhance collaboration in a very complex area for many various uses. This included identifying negative area to take advantage of every part of the building. By continuously improving the BIM model and working in $3 \mathrm{D}$, the team obtained coordination throughout disciplines and reduced design mistakes and on-site design changes.

\subsection{India - Chennai International Airport Expansion}

The fifth example is the Chennai International Airport in India, [8]. It is the $4^{\text {th }}$ busiest airport in India and the $50^{\text {th }}$ busiest airport in Asia as of 2017.

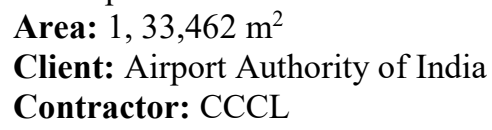

Area: $1,33,462 \mathrm{~m}^{2}$

Client: Airport Authority of India

Contractor: CCCL

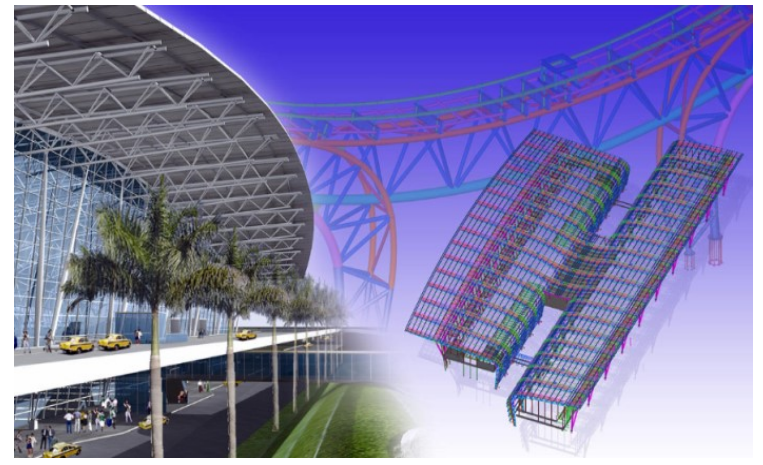

Fig. 11. Chennai International Airport Expansion, [9].

The Chennai International Project has faced a lot of issues during execution phase due to unexpected factors that induced obstacles during execution. Some of them are settled below and how BIM was an efficient instrument during execution or construction of airport terminal, [10].

The soil investigation was not good and during execution they had to go with breaking solid rock layer. Trusses designed for the project were very difficult. And as the intensity of construction work was not understood well, because of which there was an unreliable working condition. Here BIM plays an essential role, with which a correct model plan for erection scheme can be laid and worked out with safety at its best.

\footnotetext{
${ }^{5}$ Lu Wanmei, BIM Design Center Vice Director, Tianjin Architecture Design Institute
} 
The other main issue faced was the underground cable and utility lines. Excavation work was disturbed and caused delay. Same situation has been mitigated using BIM in other airport projects, and hence the delay would have been eliminated with use of underground utilities drawing in BIM. This will help in understanding the obstruction in planning phase and with no delay during execution phase.

Tekla Software was utilized for Chennai International Airport project, BIM software. Effectiveness was not as much when compared to projects executed in other developed countries. The reason is that BIM is not widely used in India for execution of Airport projects with complex design and workflow.

"Tekla Structures software in the Chennai Airport Expansion project reduced the material wastage by 3.5 to $4 \%$ and increased productivity by more than $30 \%$ ".

\subsection{BIM in the campus of the health sciences of Bellvitge of the UB}

The sixth example is the extension of the University of Barcelona, [11]

Designed surface: $11,805 \mathrm{~m}^{2}$

Client: University of Barcelona

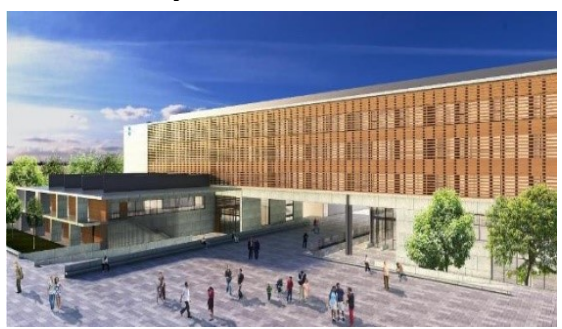

Fig. 12. Campus of the health sciences of Bellvitge, [11].

The project was developed in BIM throughout the process, from the design of the building until the completion of the work. The model was utilized to control all architectural and structural elements, and avoid conflicts between different disciplines. It was also useful to quickly obtain listings and view desired items anywhere in the building for study, ensuring coherence among them.

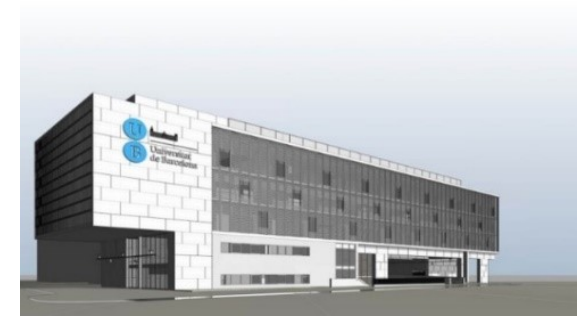

Fig. 13. University of Barcelona, [11].

During the construction process has undergone changes due to the constant updating of the BIM model, they could be seen in the model, can provide the client with changes, images showing the final result of the project. The project is divided into several phases of construction, which is strictly controlled by having them clearly differentiated in the model. With the use of BIM, it was possible to work on the project with the tranquility of not finding interference between different elements, whether architectural design and the structure.

BIM experience showed:

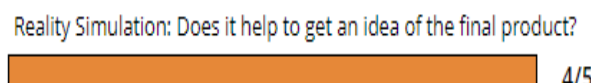

Waste reduction, labor costs and deviations

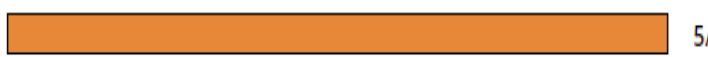

Greater control of the construction process

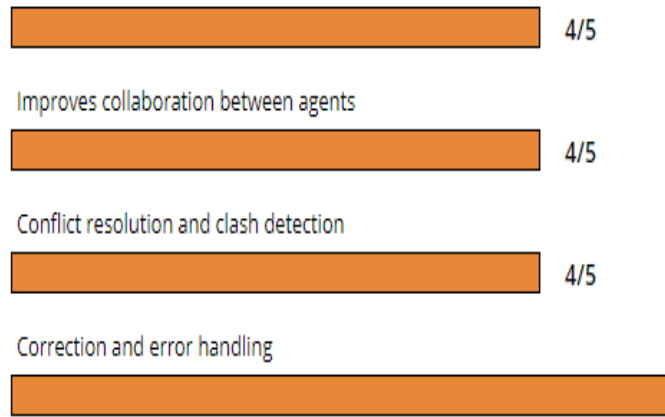

Fig. 14. BIM Experience on project UB, [11].

\subsection{The KAFD Metro Station}

Another successful example is the KAFD Metro Station, [12].

Company: AR Riyadh Development Authority

Location: Riyadh, Saudi Arabia

Area: $45000 \mathrm{~m}^{2}$

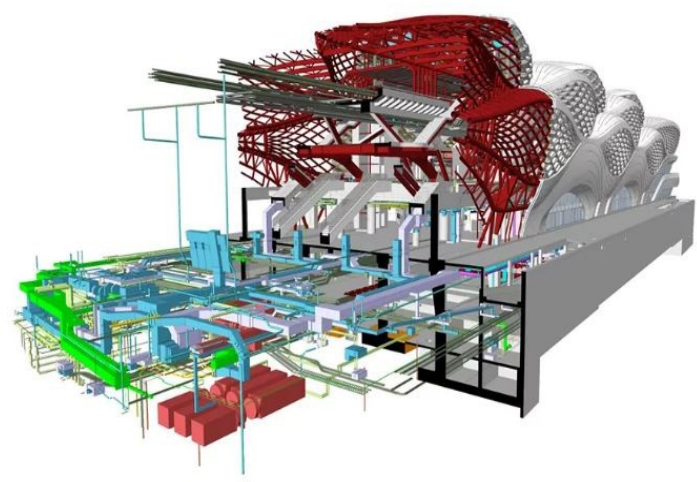

Fig. 15. The King Abdullah Finance District (KAFD), [12].

The King Abdullah Finance District (KAFD) is a $45,000 \mathrm{~m}^{2}$ metro station in Riyadh, Saudi Arabia. It is complex geometry forced Zaha Hadid Architects to develop their custom software to model the project. The goal of the station will be to interchange between three metro lines, including six platforms over four general public floors and two levels of subway car park. The project will be combined with the local financial zone and transport connections. It is a three-dimensional grid defined by a chain of opposing sine waves. This

${ }^{6} \mathrm{~K}$. Mahadevan, head of Yugasoft 
complicated and rounded geometry was impossible to model in Autodesk Revit, so the Zaha Hadid Architects team decided to develop their custom BIM software to work with it.

BIM was generally used in the construction of KAFD to save money and time on site. There was necessary to create an extensive BIM Execution Plan because the customer required data compilations at special stages to guarantee the project plan did not fall behind. The AR Riyadh Development Authority plans to use the fully coordinated model, including the architecture, MEP and structures along the lifecycle of the building, and the use by its facilities management teams.

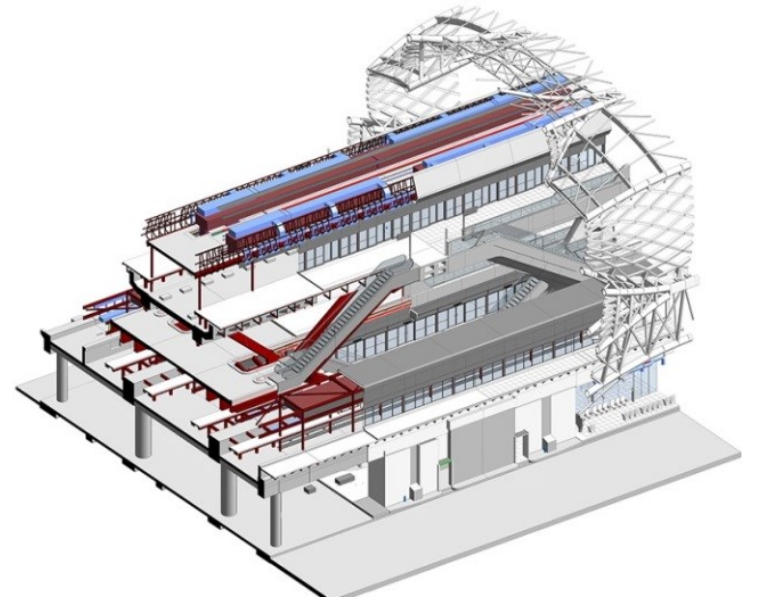

Fig. 16. King Abdullah Finance District, [12].

BIM experience in the project showed:

Reality Simulation: Does it help to get an idea of the final product?

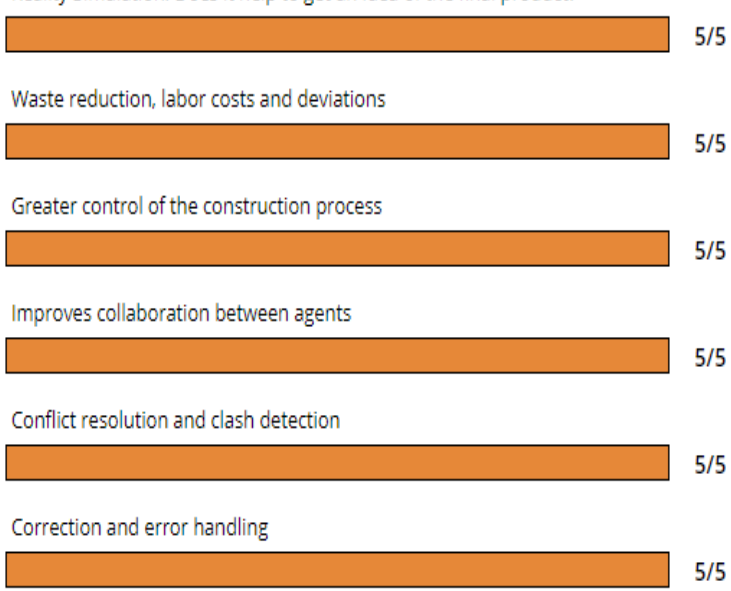

Fig. 17. BIM Experience on project KAFD, [12].

The main benefit of working with BIM has been to mitigate the project risk because the team was able to supply a total federated and coordinated model in a soft stage, including MEP and structures, which provided the client and contractor a large support in the building. The project is presently on site and the main builder is using 4D and 5D BIM processes to plan sequences of work and determine the cost of materials. The project will be finished in 2020 .

\section{Benefits of BIM}

One of the main benefits of BIM is the cost savings generated by using the virtual prototype model to highlight and remove potential problems before the construction stage, in essence helping to visualize problems which before may have been unseen. Better understanding and subsequent refining of the project from the collaboration of design data helps to minimize problems later in construction.

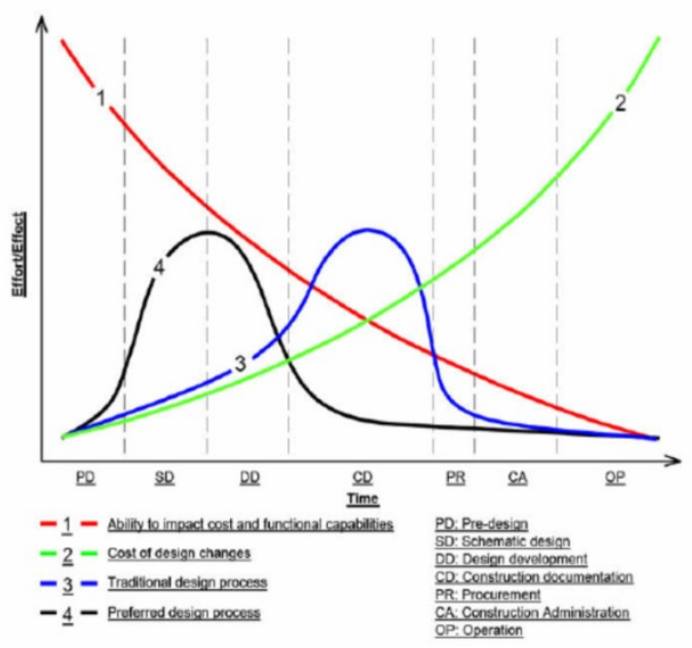

Fig. 18. Patrick MacLeamy's Effort Curve, [13].

Problems identified and resolved at an earlier stage are much less than the cost of fixing them later in the construction process. This is emphasized in the curve MacLeamy, which illustrates the possibility to reduce the cost of the project, in the case of making informed decisions can be made earlier in the design phase, [3].

Reducing risk from the unexpected ground conditions should be a most aspect of the geotechnical design process. Soil problems are one of the most reasons of project delay and when they occur they are normally difficult and costly to correct.

\subsection{Benefits of incorporating geotechnical data into the BIM}

One of the main advantages of BIM is the ability to simulate various options and improve the design in order to minimize the risks in the construction process. BIM allows a way to optimize the virtual world of design and to decrease the uncertainty and risk.

BIM models frequently appear to start from the ground up. Soil is never uniform and can differ completely between locations. The role of the geotechnical team is to minimize the risk in construction. BIM is also a useful instrument in helping to optimize the stages of construction.

$\mathrm{BIM}$ is also an important instrument in helping to optimise the phases of construction as can be seen on examples presented above. By having geotechnical information such as the geology predictions, groundwater conditions accessible to the design team's important 
information on the suitability for reuse can be determined and incorporated.

BIM is not only suitable for the design and construction, but also during the entire project life cycle. After what the project is completed, BIM becomes an exact model of the assets constructed. This allows customers to understand and control what needs to be supported or upgraded to fully active.

\subsection{Benefits of BIM to geotechnical team}

BIM is not a one-way flow of information. BIM is a twoway process and, it is not just a case of putting information into BIM, but importantly, receiving information out.

An important role of BIM is to help communicate and collaborate. Having access to the latest site models and a series of data that can include map data and remote sensing, the geotechnical team can see both the overall picture and the details of the project.

The geotechnical team can optimize the different stages of site investigation, having a clear picture of the proposed design and full project information. Great performance and quality improvements can be seen with well-planned data management and strategy.

\section{Conclusion and recommendation}

One of the major benefits of BIM is cost savings by reducing unexpected problems. This highlights the need for a quality site investigation to reduce future risk and uncertainty as part of the BIM process. BIM also improves safety situation of site.

Many geotechnical teams are not delivering geotechnical data to BIM systems as they are allow to separate the almost and the interpreted data and are disquieted by the possibility of the interpretative data being misused.

Not supplying any information to the BIM team however is probably to raise the risk to the project and not aid the geotechnical team takes the communication that early and via site study can lower risks to a BIM project.

A BIM methodology is also very helpful to the Geotechnical team. The concepts of information sharing, collaboration, central information management all use. Big improvements in effectiveness and quality can be seen by having a well-planned data and management strategy.

BIM will play a big role in construction teams in the near future and give geotechnical teams the opportunity to share their vision and challenges in the ground at the beginning of the projects supposed maintain life. This is definitely what geotechnical teams want, and so they need to be embraced by BIM and help step forward in our industry.

\section{References}

1. W. Jeffrey, Ouellette, Assoc. AIA, IES NBIMS-US V3 Project Committee

http://www.nationalbimstandard.org/
2. G.R. Morin, Geotechnical BIM: Applying BIM principles to the subsurface, https://www.autodesk.com/autodeskuniversity/article/Geotechnical-BIM-ApplyingBIM-Principles-Subsurface-2018

3. R.J. Chandler, I.D. McGregor, G.R. Morin, The role of geotechnical data in Building Information Modelling, Australian - New Zealand Conference on Geomechanics, (2012)

4. Skanska, Case study: Connect Plus and M25, UK, (2009)

https://www.skanska.co.uk/expertise/projects/57004 /M25-Motorway $\% 2 \mathrm{C}-\mathrm{UK}$

5. J. Desai, Life Cycle Director, Skanska Infrastructure Development, (2009), https://group.skanska.com/48e49c/globalassets/abou t-us/building-information-modeling/bimprojects/bim-m25-widening.pdf

6. Bentley Systems, (October 9, 2017), https://www.bentley.com/en/aboutus/news/2017/october/09/ai-16-armur-bridge

7. AEC Excellence Awards, (2017), https://www.autodesk.com/solutions/bim/hub/aecexcellence-2017/building/second-place

8. Wikipedia information regarding Chennai International Airport https://en.wikipedia.org/wiki/Chennai_International Airport

9. Yugasoft, Tekla BIM Awards, (2010) https://www.tekla.com/references/chennai-airportexpansion\#

10. S. Giridharan, A. Thomas, Adaptability of BIM in India's Aviation sector Projects, International Journal of Engineering Research \& Technology (IJERT) Vol. 2 Issue 9, (September - 2013) https://www.researchgate.net/profile/Albert Thomas 3/publication/319761133 Adaptability of BIM in India $\% 27 \mathrm{~s}$ Aviation sector_Projects/links/59bbd36 ca6fdcca8e5620d28/Adaptability-of-BIM-in-IndiasAviation-sector-Projects.pdf

11. BIM Community, Pinearq S.L.P, (2013) https://www.esbim.es/casos-de-exito/campus-de-lasciencias-de-la-salud-de-bellvitge-de-la-ub/

12. Stephen Cousins, Case study: KAFD Metro Station, Riyadh, Newsletter CIOB, (25 February, 2018), http://www.bimplus.co.uk/projects/complex-designdemands-bespoke-approach/

13. P. MacLeamy, Effort/Effect Curve, HOK, p. 4, (2004) 